\title{
Cyclic AMP and the preparation of the mouse uterus for implantation
}

\author{
F. T. G. Webb \\ Physiological Laboratory, Downing Street, Cambridge CB2 3EG, U.K.
}

\begin{abstract}
Summary. Experiments are described that demonstrate the ability of dibutyryl cyclic AMP (dcAMP) to induce oestrogen-like changes in the uteri of ovariectomized mice treated with progesterone. A single intraluminal injection of $6.14 \mu \mathrm{g} \mathrm{dcAMP}$ in 0.02 $\mathrm{ml}$ phosphate-buffered saline promoted cell division in the uterine stroma and sensitized the endometrium so that a decidual reaction could be induced by a subsequent injection of arachis oil into the uterine lumen. Since dcAMP has already been shown to induce implantation of diapausing mouse blastocysts in the absence of oestrogen, it is suggested that cyclic AMP is involved in egg implantation in rodents.
\end{abstract}

\section{Introduction}

Sensitization of the uterus of the intact pregnant mouse occurs as a result of the action of 'nidatory' oestrogen on the progesterone-dominated endometrium. Sensitization is essential for the initiation of the decidual reaction at the time of implantation and can be achieved in the ovariectomized mouse by exogenous administration of oestradiol after 2 or more days of treatment with progesterone (Finn, 1966; Finn \& Martin, 1972).

A normal decidual reaction, indicating uterine sensitization, is observed when embryos in the uteri of ovariectomized mice treated with progesterone implant following intraluminal injection of cyclic AMP (Holmes \& Bergström, 1975), or its dibutyryl analogue (Webb, 1975a). Webb (1975a) has provided evidence which suggests that dibutyryl cyclic AMP (dcAMP) acts locally on the embryo, the uterus, or both, but it is unclear whether sensitization results from a direct action of the nucleotide on the endometrium or whether the presence of the embryo is essential. The possibility that oestrogen synthesized by the blastocyst (Dickmann \& Dey, 1974; Dickmann, Dey \& Sen Gupta, 1975) in response to dcAMP causes local sensitization, cannot be ignored.

If dcAMP can substitute for oestrogen in sensitizing the progestational uterus, then there are several well-known oestrogen-dependent effects prior to and essential for sensitization which dcAMP might be expected to reproduce. During normal pregnancy in the mouse, oestrogen stimulates cell proliferation in the endometrium (Martin \& Finn, 1968) and induces changes in the morphology of the luminal epithelium (Martin, Finn \& Carter, 1970). The present paper concerns experiments to determine whether dcAMP can mimic these oestrogenic effects and sensitize the progestational endometrium in the mouse.

\section{Materials and Methods}

Virgin adult female mice from a closed colony of the A2G strain were ovariectomized and left for at least 20 days before further treatment. These are referred to as long-term ovariectomized mice. Virgin females from inbred CBA and C57BL stocks and from the A2G colony were mated to vasectomized males of the same strain, the presence of a vaginal plug being taken to indicate Day 1 of pseudopregnancy, and ovariectomized on Day 3 of pseudopregnancy.

Oestradiol-17 (Sigma) and progesterone (Koch-Light Laboratories) were injected subcutaneously in $0.05 \mathrm{ml}$ maize oil. $\mathrm{N}^{6}, \mathrm{O}^{2}$-dibutyryl adenosine $3^{\prime}, 5^{\prime}$-monophosphate (dcAMP: Sigma) was dissolved in phosphate-buffered saline (PBS: Dulbecco \& Vogt, 1954) to make a $1.25 \mathrm{mM}$-solution and $0.02 \mathrm{ml}$ $(12.32 \mu \mathrm{g}$ dcAMP) was injected into the uterine lumen. To initiate the decidual reaction, $0.02 \mathrm{ml}$ 
arachis oil was injected into the uterine lumen (Finn, 1966). All intraluminal injections were into the left uterine horn by way of the uterotubal junction.

At autopsy, uteri were excised, trimmed of fat and separated at the cervix. Each horn was fixed in Bouin's fluid (cell division experiments) or weighed and then fixed (decidual reaction experiments). All horns were embedded in Fibrowax (R. A. Lamb Ltd, 8 Sunbeam Rd, London NW10), sectioned at $8 \mu \mathrm{m}$ and examined histologically after staining in Mayer's haemalum and light green.

Cells in mitosis were arrested in metaphase by a single intraperitoneal injection of $0.1 \mathrm{mg}$ demecolcine (Colcemid: Ciba) in $0.05 \mathrm{ml}$ PBS $2 \mathrm{~h}$ before autopsy. After sectioning and staining, mitotic figures were counted, using a modification of the technique described by Finn \& Martin (1967), in 30 sections chosen at random from each uterine horn. In any one section, all cells undergoing mitosis in the luminal and glandular epithelum were counted. For the stromal counts, two fields $(\times 400$ magnification) on each side of the uterine lumen were studied (Finn \& Martin, 1967). The mean of the values obtained for the $\mathbf{3 0}$ sections gave the mitotic counts per section for one horn. Figures in the tables are the mean of these means.

Student's $t$ test was used to establish the significance of the difference between two means. Values of $P<0.05$ were taken as significant.

\section{Results}

\section{Effects of dcAMP on uterine cell division}

Long-term ovariectomized mice were given a single subcutaneous injection of $20 \mathrm{ng}$ oestradiol or $0.05 \mathrm{ml}$ maize oil, or a single intraluminal injection of $0.02 \mathrm{ml} \mathrm{dcAMP}$ solution or $0.02 \mathrm{ml}$ PBS. Other mice were given 3 daily injections of $1.0 \mathrm{mg}$ progesterone and received oestradiol, maize oil, dcAMP or PBS as above on the 3rd day of progesterone treatment. The animals were killed at various intervals after the injections as shown in Tables 1 and 2 . All mice were given Colcemid before autopsy.

After oestradiol treatment (Table 1), cell division was predominantly in the epithelial tissues of the uterus as has been reported by Martin \& Finn (1968). The maximum response was obtained $24 \mathrm{~h}$ after the injection of the steroid, which agrees with the findings of Martin \& Pollard (cited in Martin \& Finn, 1971). Maize oil alone had no effect. dcAMP also induced cell division predominantly in the

Table 1. The numbers of dividing cells* in the uteri of ovariectomized mice at various times after a single injection of oestradiol-17ß or dibutyryl cyclic AMP

\begin{tabular}{|c|c|c|c|c|c|c|}
\hline \multirow[b]{3}{*}{ Group } & \multirow{3}{*}{$\begin{array}{l}\text { No. of } \\
\text { mice }\end{array}$} & \multirow{3}{*}{$\begin{array}{l}\text { Compound } \\
\text { injected }\end{array}$} & \multirow{3}{*}{$\begin{array}{c}\text { Time } \\
\text { before } \\
\text { autopsy } \\
\text { (h) }\end{array}$} & \multicolumn{3}{|c|}{ No. of dividing cells/section } \\
\hline & & & & \multicolumn{2}{|c|}{ Epithelium } & \multirow[b]{2}{*}{ Stroma } \\
\hline & & & & Lumen & Glands & \\
\hline 1 & 4 & Oil vehicle & 24 & 0.0 & 0.0 & 0.0 \\
\hline 2 & 5 & Oestradiol & 6 & $0.02 \pm 0.02$ & $0.06 \pm 0.02$ & 0.0 \\
\hline 3 & 6 & Oestradiol & 12 & $0.23 \pm 0.08$ & $0.42 \pm 0.24$ & $0.27 \pm 0.19$ \\
\hline 4 & 5 & Oestradiol & 18 & $2.43 \pm 0.74$ & $1.60 \pm 0.32$ & $0.18 \pm 0.07$ \\
\hline 5 & 6 & Oestradiol & 24 & $22.07 \pm 2.59$ & $0.55 \pm 0.13$ & $0.83 \pm 0.27$ \\
\hline 6 & 8 & Oestradiol & 30 & $4.79 \pm 0.67$ & $1.21 \pm 0.31$ & $0.21 \pm 0.07$ \\
\hline 7 & 7 & Oestradiol & 36 & $5 \cdot 26 \pm 0.43$ & $1.43 \pm 0.26$ & $0.94 \pm 0.16$ \\
\hline 8 & 5 & PBS & 24 & $0.28 \pm 0.05$ & $0.62 \pm 0.09$ & $0.04 \pm 0.04$ \\
\hline 9 & 3 & dcAMP & 6 & $0.17 \pm 0.07$ & $0.33 \pm 0.09$ & $0.03 \pm 0.03$ \\
\hline 10 & 3 & dcAMP & 12 & $0.67 \pm 0.18$ & $1.33 \pm 0.20$ & $0.03 \pm 0.03$ \\
\hline 11 & 6 & dcAMP & 18 & $2.35 \pm 0.37$ & $2.93 \pm 0.20$ & $0.15 \pm 0.05$ \\
\hline 12 & 8 & dcAMP & 24 & $2.65 \pm 0.20$ & $3.80 \pm 0.31$ & $0.11 \pm 0.03$ \\
\hline 13 & 4 & dcAMP & 30 & $1.30 \pm 0.23$ & $2.38 \pm 0.13$ & $0.08 \pm 0.03$ \\
\hline 14 & 7 & dcAMP & 36 & $0.34 \pm 0.08$ & $0.21 \pm 0.11$ & $0.07 \pm 0.04$ \\
\hline
\end{tabular}

* In each uterus 30 sections were examined and the mean of this figure was used to obtain the mean \pm S.E.M. value/section. 
epithelial tissues with a maximum response after $24 \mathrm{~h}$, although the number of dividing cells in the luminal epithelium was significantly less than in oestradiol-treated controls $(P<0.001)$ and significantly more division occurred in the glandular than in the luminal epithelium $(0.005<P<0.01)$. By $24 \mathrm{~h}$ after PBS injection, some mitotic figures were observed in the endometrial tissues, but the mean number was significantly lower than in uteri receiving dcAMP $(P<0.001)$.

Table 2. The numbers of dividing cells* in the uteri of ovariectomized mice treated daily with progesterone and killed at various times after a single injection of oestradiol-17 $\beta$ or dibutyryl cyclic AMP

\begin{tabular}{|c|c|c|c|c|c|c|}
\hline \multirow[b]{3}{*}{ Group } & \multirow{3}{*}{$\begin{array}{l}\text { No. of } \\
\text { mice }\end{array}$} & \multirow{3}{*}{$\begin{array}{l}\text { Compound } \\
\text { injected }\end{array}$} & \multirow{3}{*}{$\begin{array}{c}\text { Time } \\
\text { before } \\
\text { autopsy } \\
\text { (h) }\end{array}$} & \multicolumn{3}{|c|}{ No. of dividing cells/section } \\
\hline & & & & \multicolumn{2}{|c|}{ Epithelium } & \multirow[b]{2}{*}{ Stroma } \\
\hline & & & & Lumen & Glands & \\
\hline 1 & 4 & Oil vehicle & 24 & 0.0 & 0.0 & $0.10 \pm 0.01$ \\
\hline 2 & 3 & Oestradiol & 18 & $0.17 \pm 0.08$ & $0.08 \pm 0.04$ & $37 \cdot 1 \pm 6 \cdot 6$ \\
\hline 3 & 3 & Oestradiol & 24 & $2.79 \pm 0.22$ & $0.28 \pm 0.18$ & $68.0 \pm 0.70$ \\
\hline 4 & 3 & Oestradiol & 30 & $4.73 \pm 0.5$ & $0.17 \pm 0.09$ & $11.87 \pm 0.59$ \\
\hline 5 & 3 & PBS & 24 & $0.23 \pm 0.03$ & $0.33 \pm 0.2$ & $0.23 \pm 0.07$ \\
\hline 6 & 3 & dcAMP & 13 & $1 \cdot 13 \pm 0.20$ & $0.13 \pm 0.07$ & $7.73 \pm 1.4$ \\
\hline 7 & 3 & dcAMP & 18 & $0.13 \pm 0.07$ & $1.0 \pm 0.3$ & $4.87 \pm 1.1$ \\
\hline 8 & 3 & dcAMP & 24 & $11 \cdot 1 \pm 0.3$ & $0.67 \pm 0.2$ & $20.53 \pm 0.8$ \\
\hline 9 & 3 & dcAMP & 31 & $2.9 \pm 0.4$ & $0.5 \pm 0.3$ & $15.93 \pm 0.6$ \\
\hline 10 & 3 & dcAMP & 36 & $1.13 \pm 0.3$ & $0.13 \pm 0.07$ & $3.63 \pm 0.3$ \\
\hline
\end{tabular}

* See legend to Table 1 .

When oestradiol injection was preceded by progesterone treatment (Table 2), cell divisions were observed in the stromal tissues, reaching a maximum at $24 \mathrm{~h}$ and again confirming the findings of Martin \& Finn (1968). When progestational uteri were treated with dcAMP, the absolute numbers of dividing cells appeared more comparable to those seen after treatment with oestradiol although still significantly less $(P<0.001)$. PBS induced some cell division, but less than dcAMP $(P<0.001)$. Maize oil was without effect.

\section{Effects of dcAMP on epithelial morphology}

The histological preparations of the previous experiments were studied to assess the effects of dcAMP, with and without pretreatment with progesterone, on the morphology of the uterine luminal epithelium. The effects were compared to those seen in the corresponding oestradiol controls and reference was made to the work of Martin et al. (1970).

By 3 weeks after ovariectomy, the luminal epithelium of the atrophied uteri had become thin, and the regularly aligned nuclei were small and without prominent nucleoli. Some subnuclear vacuolation was evident. After treatment with dcAMP alone there was virtually no change, whereas within $24 \mathrm{~h}$ of oestradiol injection epithelial cell height had increased markedly, nuclei were elongated, randomly aligned and contained prominent nucleoli. Subnuclear vacuolation had almost disappeared. The luminal epithelium of uteri receiving treatment with progesterone before dcAMP injection appeared remarkably similar to that seen in the corresponding oestradiol controls: epithelial cell height increased, nuclei were small without prominent nucleoli and were aligned almost as regularly as in untreated controls. There was extensive subnuclear vacuolation. The surface of the epithelium appeared corrugated (Finn \& McLaren, 1967), indicating that the conditions for luminal closure were achieved (Martin et al., 1970). Similar effects were seen in uteri which, after treatment with progesterone, received only PBS intraluminally, although the increase in cell height and corrugations was not as marked as with dcAMP or oestradiol. The ability of progesterone alone to induce these changes in the luminal epithelium has also been noted by Martin et al. (1970). 


\section{Induction of endometrial sensitivity by dcAMP}

Pseudopregnant mice were treated as shown in Table 3 and long-term ovariectomized mice were given ovarian steroids according to the schedule shown in Table 4 (modified from Finn \& Martin, 1972). In all animals, arachis oil was injected $7 \mathrm{~h}$ after the final injection of oestradiol or the administration of dcAMP or PBS. Intraluminal injections were to the left horn whilst a sham operation, involving uterine puncture but no injection, was performed on the right horn. At autopsy $48 \mathrm{~h}$ later, uteri were examined for evidence of decidualization. Small swellings invariably seen at the uterotubal. junction, which the sham operations showed to be due to the trauma of the injection, were ignored.

In the hormonally prepared and ovariectomized pseudopregnant mice, intraluminal administration of dcAMP was able to complete the sensitization of the progesterone-dominated uterus so that a normal decidual reaction could be induced by the arachis oil. In each experiment, most uteri treated with dcAMP showed macroscopic and histological evidence of decidualization which appeared to be progressing normally. There was no difference in the mean uterine weights of pseudopregnant mice treated with oestradiol or dcAMP $(P>0.5)$. The mean weight of uterine horns of long-term ovariectomized mice sensitized by dcAMP appeared lower than that of the equivalent oestrogen controls although this difference was also not significant $(0.2<P<0.4)$. None of the uteri treated with PBS showed histological evidence of a decidual reaction.

\section{Discussion}

These studies demonstrate the ability of dcAMP to induce oestrogen-like changes in the progesteronedominated mouse uterus. By $24 \mathrm{~h}$ after administration of dcAMP, large numbers of stromal cells: were seen to undergo mitosis and the luminal epithelium showed morphological changes characteristic of those seen after oestradiol treatment. These proliferative and morphological events can be observed in the uterus of the intact mouse shortly before implantation (Finn \& Martin, 1967; Finn \& McLaren, 1967) and are believed to be essential features of the preparation of the endometrium for implantation (Finn, 1971).

In ovariectomized mice not receiving progesterone, the response to dcAMP was poor compared with that after oestradiol injection: epithelial morphology remained comparable to that of untreated controls and the mitogenic action of the two compounds differed quantitatively, there being fewer epithelial mitotic figures in the uteri treated with dcAMP. The reason for this poor response is unclear. Rath \& Prasad (1974) showed that repeated infusions of $0.05 \mathrm{ml}$ of a $1.25 \mathrm{mM}$-solution of dcAMP to the uteri of ovariectomized rats resulted in marked hypertrophy and hyperplasia of the epithelial tissues. In the present work, a single injection only was given and hydrolysis of dcAMP by phosphodiesterase may have limited the time during which the nucleotide was active, an effect which may have been circumvented by the infusions given by Rath \& Prasad (1974) every $8 \mathrm{~h}$.

Progesterone treatment followed by administration of dcAMP was also able to complete the sequence of hormonal action needed to induce uterine sensitization in spayed pseudopregnant mice and long-term ovariectomized mice primed with oestradiol. The use of long-term ovariectomized mice, in which the uterus had been allowed to atrophy before the commencement of treatment with steroids, was perhaps a more exacting test of the ability of dcAMP to sensitize the uterus. In this case, the mean weight of decidualized horns was less than that of the oestrogen-sensitized controls, although not significantly so. The lower decidual weight was attributed to the fact that fewer stromal cells were seen dividing in response to dcAMP than to oestradiol as stromal mitosis at this time would increase the number of cells available for decidualization (Finn, 1971). In ovariectomized pseudopregnant mice, in which the uteri were not allowed to atrophy, the number of stromal dividing cells may have had relatively little effect on the final weight of decidual tissue.

Sensitization of the endometrium occurs when mouse embryos in diapause implant after a single injection of dcAMP (Webb, 1975a). It is unlikely that this sensitization is a result of local action of the embryos, perhaps through oestrogen produced by the blastocysts (Dickmann \& Dey, 1974; Dickmann et al., 1975), as the present results indicate that dcAMP can induce sensitization in the absence of embryos. The rise in cyclic AMP seen at the time of implantation in rats (J. O'Grady, personal 

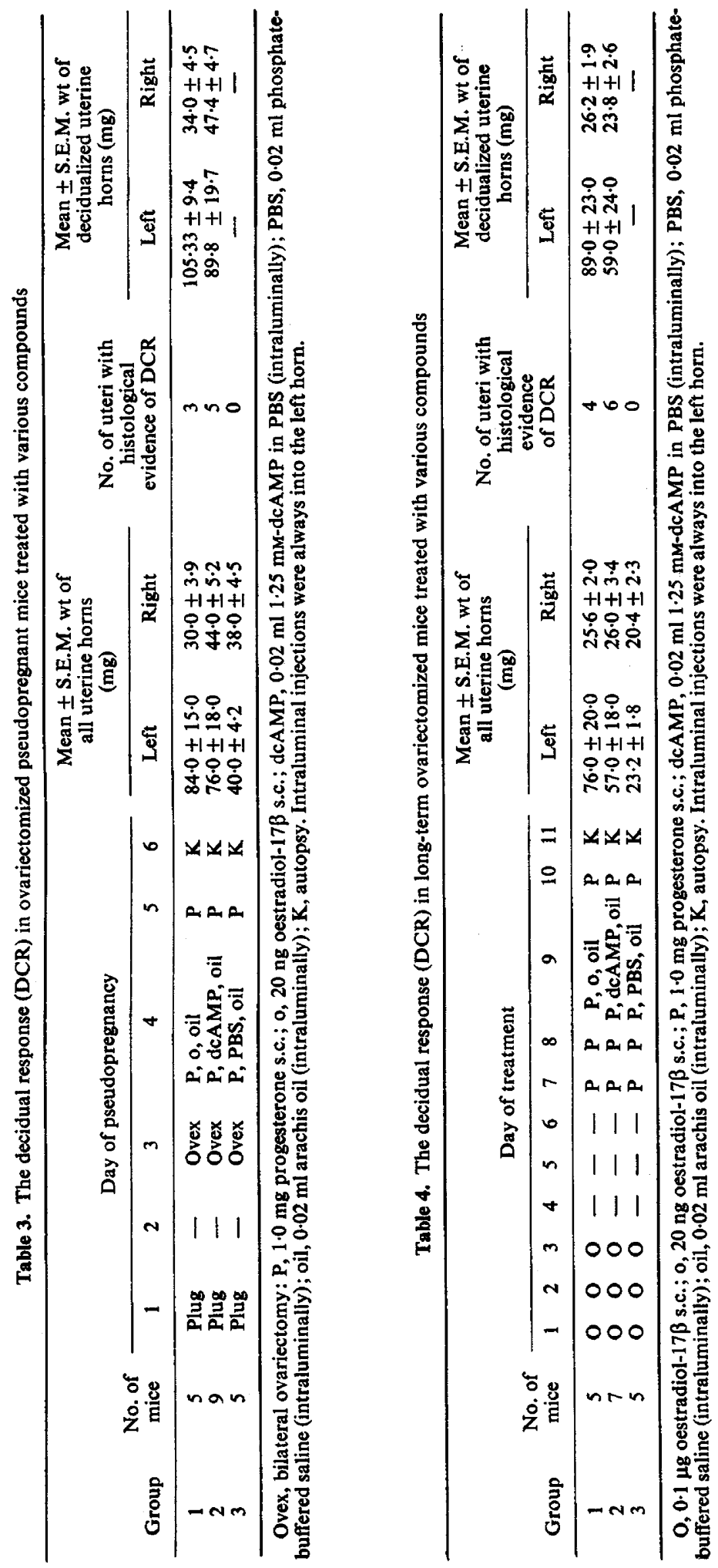
communication) provides additional circumstantial evidence for the involvement of the nucleotide in implantation in rodents. The mechanism by which oestrogen could increase cyclic AMP levels is unclear, although it could be secondary to the release of biogenic amines, such as histamine which exerts its action by stimulation of adenyl cyclase (see Singhal, 1973). Histamine is known to be released during early oestrogen action (Spaziani \& Szego, 1958; Shelesnyak, 1959a; McKercher, Van Orden, Bhatnagar \& Burke, 1973) and uterine histamine levels fall at the time of implantation (Shelesnyak, 1959b). These observations led Shelesnyak, Marcus \& Lindner (1970) to suggest a role for histamine as the mediator of the decidual stimulus, but both histamine (see Finn, 1971) and cyclic AMP (Webb, 1975b) have now been shown not to be involved in evoking the response. On the other hand, the present results are compatible with a role for histamine in sensitization of the uterus in preparation for the decidual response, an idea supported by the observations of Ferrando \& Nalbandov (1968) who showed that implantation could not take place in the absence of uterine mast cells which are the only known source of uterine histamine (McKercher et al., 1973).

It remains to be seen whether, when implantation follows dcAMP treatment, the resumption of metabolic activity and development of the diapausing embryos result from a direct effect of the dcAMP on the blastocysts as suggested by Mohla \& Prasad (1970), or an indirect effect resulting from action of the dcAMP on the uterus (Webb \& Surani, 1975). The ability of dcAMP to induce sensitization suggests that this compound may also substitute for oestrogen in promoting the synthesis of the uterine-specific proteins associated with implantation which may play a part in modulating blastocyst metabolic activity in rats (Surani, 1975, 1976; Webb \& Surani, 1975) and mice (GoreLangton \& Surani, 1976). This possibility is being further investigated.

The work was supported by a grant from the Medical Research Council. It is a pleasure to acknowledge invaluable discussions with Christopher Graham, Azim Surani and Robert Gore-Langton.

\section{References}

Dickmann, Z. \& DEY, S.K. (1974) Steroidogenesis in the preimplantation rat embryo and its possible influence on morula-blastocyst transformation and implantation. J. Reprod. Fert. 37, 91-93.

DickmanN, Z., Dey, S.K. \& Sen Gupta, J. (1975) Steroidogenesis in rabbit preimplantation embryos. Proc. natn. Acad. Sci. U.S.A. 72, 298-300.

Dulbecco, R. \& Vogt, M. (1954) Plaque formation and isolation of pure lines with poliomyelitis virus. $J$. exp. Med. 99, 167-182.

Ferrando, G. \& Nalbandov, A. V. (1968) Relative importance of histamine and estrogen on implantation in rats. Endocrinology 83, 933-937.

FinN, C.A. (1966) Endocrine control of endometrial sensitivity during the induction of the decidual cell reaction in the mouse. $J$. Endocr. 36, 239-248.

FinN, C.A. (1971) Biology of decidual cells. Adv. Reprod. Physiol. 5, 1-26.

Finn, C.A. \& Martin, L. (1967) Patterns of cell division in the mouse uterus during early pregnancy. $J$. Endocr. 39, 593-597.

FINN, C.A. \& MARTIN, L. (1972) Endocrine control of the timing of endometrial sensitivity to a decidual stimulus. Biol. Reprod. 7, 82-86.

FinN, C.A. \& MCLAREN, A. (1967) A study of the early stages of implantation in mice. J. Reprod. Fert. 13, 259-267.

Gore-Langton, R.E. \& Surani, M.A.H. (1976) Uterine luminal proteins of mice.J. Reprod. Fert. 46, 271-274.
Holmes, P.V. \& Bergström, S. (1975) Induction of blastocyst implantation in mice by cyclic AMP. J. Reprod. Fert. 43, 329-332.

MARTIN, L. \& FINN, C.A. (1968) Hormone regulation of cell division in epithelial and connective tissue of the mouse uterus. J. Endocr. 41, 363-371.

MARTIN, L. \& FINN, C.A. (1971) Oestrogen-gestagen interactions on mitosis in target tissues. In Basic Actions of Sex Steroids on Target Organs, pp. 172188. Eds P. O. Hubinont, F. Leroy \& P. Galand. Karger, Basel.

Martin, L., Finn, C.A. \& Carter, J. (1970) Effects of progesterone and oestradiol-17 $\beta$ on the luminal epithelium of the mouse uterus. J. Reprod. Fert. 21, 461-469.

Mckercher, T.C., Van Orden, L.S., Bhatnagar, R.K. \& BURKE, J.P. (1973) Estrogen-induced biogenic amine reduction in rat uterus. $J$. Pharmac. exp. Ther. 185, 514-522.

Mohla, S. \& Prasad, M.R.N. (1970) Stimulation of RNA synthesis in the blastocyst and uterus of the rat by adenosine 3', 5'-monophosphate (cyclic AMP). J. Reprod. Fert. 23, 327-329.

RATH, N.C. \& PRASAD, M.R.N. (1974) Action of cyclic 3',5'-adenosine monophosphate on the uterus of the ovariectomized rat. Fert. Steril. 25, 724730.

Shelesnyak, M.C. (1959a) Histamine releasing activity of natural estrogens. Proc, Soc. exp. Biol. Med.100, 739-741. 
Shelessyak, M.C. (1959b) Fall in uterine histamine associated with ovum implantation in the pregnant rat. Proc. Soc. exp. Biol. Med. 100, 380-381.

Shelesnyak, M.C., Marcus, G.J. \& LindneR, H.R. (1970) Determinants of the decidual reaction. In Ovo-implantation, Human Gonadotropins and Prolactin, pp. 118-129. Eds P. O. Hubinont, F. Leroy, C. Robyn \& P. Leleux. Karger, Basel.

Singhal, R.L. (1973) Cyclic adenosine 3',5'-monophosphate and estrogenic stimulation of uterine metabolism. Adv. Pharmac. \& Chemother. 11, 99150.

Spaziani, E. \& Szego, C.M. (1958) The influence of estradiol and cortisol on uterine histamine of the ovariectomized rat. Endocrinology 63, 669-677.

SuRAN, M.A.H. (1975) Hormonal regulation of proteins in the uterine secretion of ovariectomized rats and the implications for implantation and embryonic diapause. J. Reprod. Fert. 43, 411-417.
SURANI, M.A.H. (1976) Uterine luminal proteins at the time of implantation in rats. J. Reprod. Fert. 48, 141-145.

WeBB, F.T.G. (1975a) Implantation in ovariectomized mice treated with dibutyryl adenosine $3^{\prime}, 5^{\prime}$-monophosphate (dibutyryl cyclic AMP). J. Reprod. Fert. 42, 511-517.

WeBB, F.T.G. (1975b) The inability of dibutyryl adenosine $3^{\prime}, 5^{\prime}$-monophosphate to induce the decidual reaction in intact pseudopregnant mice. J. Reprod. Fert. 42, 187-188.

Webe, F.T.G. \& SuranI, M.A.H. (1975) Influence of environment on blastocyst proliferation, differentiation and implantation. In Regulation of Growth and Differentiated Function in Eukaryote Cells, pp. 519522. Ed. G. P. Talwar. Raven Press, New York.

Received 3 November 1976 